\title{
Administration of curcumin affects the anxiety behavior in Wistar rats after formaldehyde injected
}

\author{
Mouna Nouacer $^{\mathrm{a} *}$ (i) $\mid$ Amira Bakeche ${ }^{\mathrm{a}}$ (D) | Ibtissem Chouba ${ }^{\mathrm{a}}$ | Abdelkrim Tahraoui ${ }^{\mathrm{a}}$
}

Applied Neuroendocrinology Laboratory, Department of Biology, Faculty of Sciences, University Badji Mokhtar, Annaba, Algeria.

Corresponding author: mouna.nouacer23@hotmail.com

\begin{abstract}
The curcumin is part of the curcuminoids family. Present in the spice turmeric is a vegetable alkaloid obtained from Curcuma longa. Many studies have been carried out to describe the multiple biological actions of curcumin. The positive antidepressant and anti-anxiety effects of curcumin are most likely due to its ability to normalize specific physiological mechanisms, in addition to being a potent antioxidant and anti-inflammatory agent. Curcumin also protects the brain and simultaneously acts on several mechanisms related to depression. It is considered to be the most promising therapeutic target for treating depressive behaviors. Through this work, we will prove the protective effect of curcumin on the anxious behavior of Wistar rats and the complications induced by the administration of a toxic product that is formaldehyde. To this fact, 25 white rats of Wistar strains $(250 \pm 50 \mathrm{~g})$ were separated into five experimental batches: control batch $(T ; n=5)$, vehicle control batch $(C V ; n=5)$, Curcumin control batch (CC; $n=5)$, one batch formaldehyde vehicle $(F V ; n=5)$ and one batch formaldehyde Curcumin (FC; $n=5)$. A single intraperitoneal injection carried out the formaldehyde administration diluted in distilled water at a dose of $10 \mathrm{mg} / \mathrm{kg}$. Turmeric dissolved in olive oil was administered by gastric gavage at a dose of $(60 \mathrm{mg} / \mathrm{kg})$. Our results show the therapeutic benefits of curcumin against the deficits caused by formaldehyde reflected in a disturbance in rat behavior and degree of anxiety using the open-field test and the light and dark box test.
\end{abstract}

Keywords animal behavior, anxiety, Curcuma longa, open-field test, tumeric

\section{Introduction}

Curcumin (CUR) is a frequent spice used in the diets of Asians, like India or China. Its antioxidant and antiinflammatory properties have been exploited for centuries for the treatment of several chronic diseases. Besides, its usefulness as a complementary treatment in several neuropsychiatric disorders has been reported by several authors; the number of trials testing its effectiveness in mental health conditions has steadily increased over the years, both in animal models and in humans. Because of these properties, it has been speculated that curcumin may help treat depression, affecting millions worldwide (World Health Organization 2017).

CUR has been used for centuries in medicines to treat a variety of inflammatory symptoms. It is a commonly used spice as it is increasingly studied for its antidepressant effect. (Lopresti and Drummond 2017). CUR has also shown anxiolytic-like effects on the biochemistry and behavioral symptoms associated with anxiety (Lee and Lee 2018).

Anxiety is a common and potentially serious condition that can significantly affect individuals' quality of life and predispose them to psychiatric comorbidities. Depression is a consequence of anxiety, affecting $21 \%$ of populations (Esmaily et al 2015).

Epidemiological studies show that people complain of a series of neuropsychiatric symptoms, such as depression, anxiety, sleep disturbances, malaise, balance dysfunctions, headaches, indigestion, lethargy, decreased motor activity, and loss of appetite. These further confirmed that neuropsychiatry symptoms are closely related to long-term exposure to formaldehyde in the air (Wang et al 2017).

The formaldehyde, better known as formalin when dissolved in water, is a highly volatile organic compound belonging to the aldehyde family. Low molecular weight, this substance has the property of becoming gaseous at room temperature and is currently frequently found in indoor environments (Erika 2015).

Formaldehyde is known to have these deleterious effects on human health (Lan et al 2015). The commercially available formaldehyde contains $37-41 \%$ formaldehyde, classified as carcinogenic to humans (Hoque 2018).

In this context, our study aims to assess the protective effect of the natural molecule (curcumin) against the harmful effects induced by formaldehyde through behavioral tests aiming to verify the rats' possible presence of central nervous functions.

\section{Materials and Methods}

\subsection{Biological material}

The experimental study was carried out on 25 white rats of the Wistar strain, weighing on average $150 \mathrm{~g}$ on their arrival ( $250 \pm 50$ grams). These animals were acclimatized to animal housing conditions at a temperature of $25 \pm 2{ }^{\circ} \mathrm{C}$; the animals were reared in polyethylene cages lined with litter made from wood chips. The cages were cleaned, and the litter changed once every two days. Feed brought to the 
animals was made in the form of sticks made of corn, barley, milk, and vitamin supplements. Drinking water was presented in bottles adapted to the cages. Food and water are provided ad libitum. After an adaptation period of 4weeks, the rats were separated into five experimental groups: control batch $(T ; n=5)$, vehicle control batch $(C V ; n=$ 5), Curcumin control batch (CC; $n=5)$, one batch formaldehyde vehicle (FV; $n=5)$ and one batch formaldehyde Curcumin ( $F C ; n=5$ ). The whole approach described is in agreement with the University of Badji Mokhtar's ethics guidelines-Annaba.

\subsection{The light/dark box test}

The light/dark box test is based on Crawley and Goodwin's original model (1980). This test encountered the conflict between rodents' natural urge to explore their fear of light. They naturally prefer dark places while avoiding bright places (Ben Ahmed 2016). The test was carried out in a box divided into two compartments, one compartment painted in black and the other in white illuminated by daylight. There is an opening that serves as a door that has been created between the two zones to facilitate the easy movement of the animal from one region to another. First, the rat was placed in the lighted compartment at this time and start filming the test for 5 minutes in two sessions, on day 7 and day 14, using a high-performance camera.

\subsection{Test of the open-field (OF)}

The test was described by Hall (1934) to measure differences in emotional reactivity. The device consists of a square base surrounded by plexiglass walls with $70 \times 70 \times 40$ $\mathrm{cm}$. The test was based on the rat's delicate placement, picking it up by the field's center queue. A high-capacity camera filmed the evolution of its behavior for 5 minutes in 2 sessions on day 7 and day 14 . At the end of each test, the rat was removed and clean entirely with a $70 \%$ alcohol solution and dry with absorbent paper. Its movement makes it possible to measure the time spent in the peripheral zone and the central zone. Therefore, this test indicates the anxious behavior of the rats.

\subsection{Administration of formaldehyde}

The administration of formaldehyde solution meets the analytical specification of USP; $\geq 34.5 \mathrm{wt}$. \% was carried out by a single intraperitoneal injection at a dose of $10 \mathrm{mg} / \mathrm{kg}$ according to Mahmoud and Fenghour (2016) after dilution with distilled water.

\subsection{Administration of antioxidants}

The curcumin used for the treatment of rats was presented as a yellow powder. Turmeric (Curcuma longa L.) was obtained in our research laboratory to prepare an adequate dose. A precision balance was used to measure a dose of $60 \mathrm{mg} / \mathrm{kg}$ depending on the rats' weight. The quantified doses were added to Eppendorf tubes to be dissolved in olive oil. Before administration, the tubes were shaken well until a homogeneous solution was obtained. The treatment began on the 8th day after the formaldehyde injection, and its administration was by gastric tube for seven days.

\subsection{Data processing}

The data were introduced then processed with the Prism software (version 6). The results are expressed as mean $\pm S E M$ and compared by a student's $t$-test at the significance level Alpha $=0.05$ then represented in histograms.

\section{Results}

\subsection{Variation of the light/dark box test parameters}

Figure 1 shows the rats' time in each box compartment, light and dark, in the two sessions on day 7 and day 14 . On day 7, the batches FV and FC spend more time in the dark compartments with a very significant difference $(P<0.01)$ compared to batch T. On day 14 , a non-significance $(P>0.05)$ between $\mathrm{FV}$ and $\mathrm{FC}$ was observed. On the other hand, a significant difference $(P<0.05)$ was noticed between FV day 7 and FV day 14, with averages of $253.0 \pm 6.95 \mathrm{~s}$ and $229.8 \pm 10.36 \mathrm{~s}$. Another very significant difference $(P<0.01)$ between FC day 7 and FC day 14 with a mean of $252.2 \pm 5.21 \mathrm{~s}$ and $211.0 \pm 6.96 \mathrm{~s}$, respectively.

On day 7 , a very significant decrease in the time spent in the clear compartment of the FV $(47.00 \pm 6.950 \mathrm{~s})$ and FC (47.80 $\pm 5.21 \mathrm{~s})$ compared to $\mathrm{T}(77.80 \pm 3.84 \mathrm{~s})$. On day 14 , a non-significance difference between FV $(70.20 \pm 10.36 \mathrm{~s})$ and FC (89.00 $\pm 6.96 \mathrm{~s})$, compared to $T(82.60 \pm 7.76 \mathrm{~s})$, was observed. There is a significant difference between FV $(47.00 \pm 6.95$ s) day 7 and FV (70.20 \pm 0.36 s) day 14 . Also, a very significant difference between FC $(47.80 \pm 5.21 \mathrm{~s})$ day 7 and FC (89.00 \pm 6.957 s) day 14 was verified.

\subsection{Variation of the open-field test parameters}

Figure 2 reveals the time spent in the two zones of the open-field test's specific device in two sessions' day 7 and day 14. The time spent in the peripheral zone, on day 7 , was a highly significant increase $(P<0.01)$ of the FV and FC (Figure $2 A)$. On day 14 , there is no significant difference between the lots, although a highly significant difference $(P<0.01)$ between the two sessions of the same batch FV (day 7 and day 14) was observed. For the batch treated with curcumin (FC), a very highly significant decrease $(P<0.001)$ was verified between day $14(229.4 \pm 6.92 \mathrm{~s})$ and day $7(283.0 \pm 5.0 \mathrm{~s})$.

Figure $2 \mathrm{~B}$ shows the time spent in the central zone and the results contrast with those of the peripheral zone. We notice a highly significant difference $(P<0.01)$ between FV $(18.80 \pm 3.65 \mathrm{~s})$ and $\mathrm{FC}(17.00 \pm 5.03 \mathrm{~s})$ when these are compared with $T(60.00 \pm 11.32 \mathrm{~s})$. On day 14 , an absence of significance between the batches was observed. A very highly significant increase $(P<0.001)$ of the batch FC on day 14 $(70.60 \pm 6.92 \mathrm{~s})$, when compared to the FC day 7 (17.00 \pm 5.03 s), was observed. 
(A)

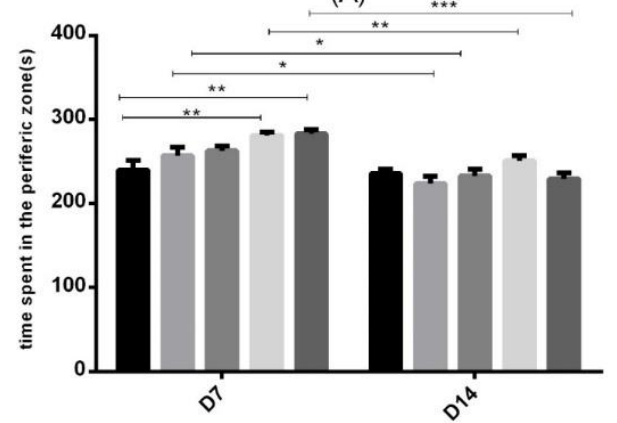

(B)

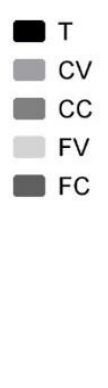

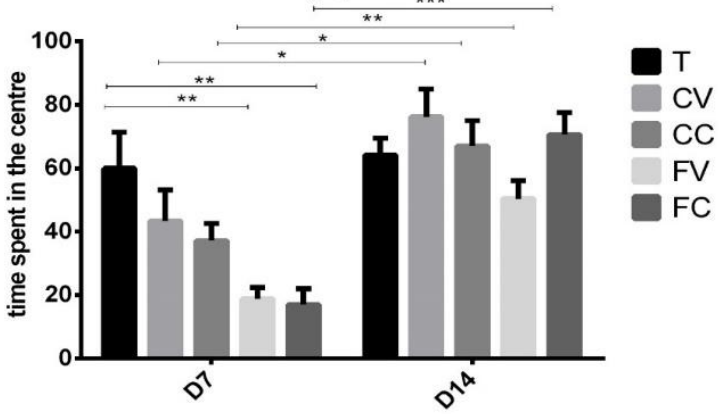

Figure 1 Time spent in the light/dark box of the batches: controls (T), vehicle control (CV), curcumin control (CC), vehicle formaldehyde (FV), and curcumin formaldehyde (FC). The results are expressed on mean \pm SEM. Ns. is non-significant difference $=P>0.05 ;{ }^{*} P<0.05 ;{ }^{* *} P<0.01 ; * * P<0.001$.
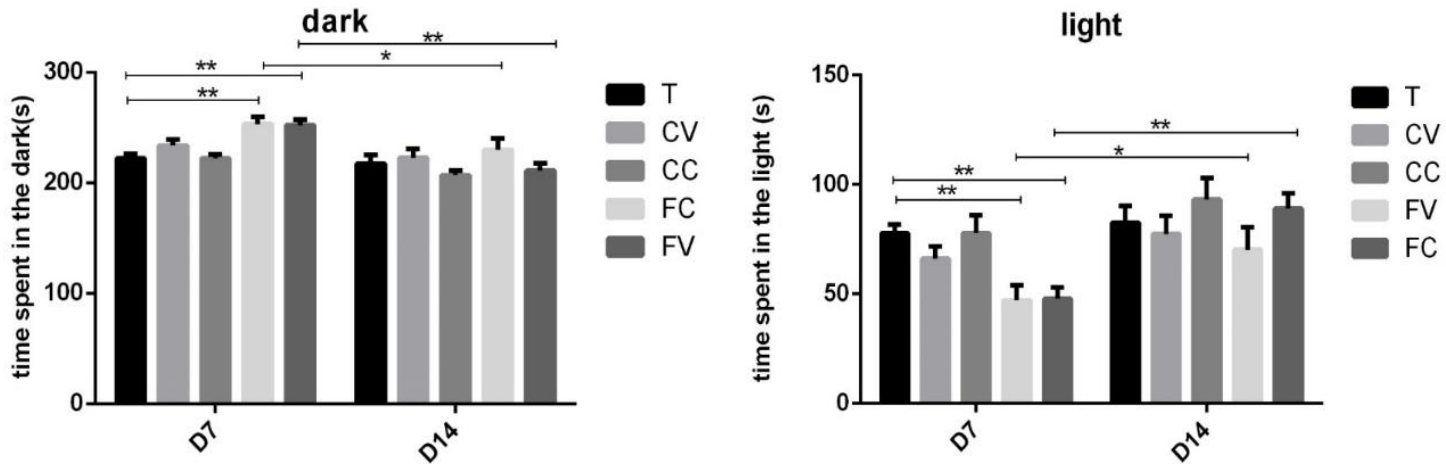

Figure 2 Time spent in the peripheral zone and the central zone of the open field of the batches: controls (T), vehicle control (CV), Curcumin control (CC), vehicle formaldehyde (FV), and curcumin formaldehyde (FC) the results are expressed as mean \pm SEM. Ns. is non-significant difference $=P>0.05 ; * P<0.05 ; * * P<0.01 ; * * * P<0.001$.

\section{Discussion}

Our research has based on two parameters of the light/dark box test: the time spent in the light compartment and the time spent in the dark chamber. We recorded on the 7 th day of the rats which were injected with formaldehyde (FV) and (FC) spend more time in the dark compartment than the clear chamber, with a very significant difference compared to the control $(T)$. It is known that mice naturally prefer dark places and avoid lighted ones. This natural behavior has been used to estimate the degree of anxiety in animals (Arrant 2013). Our results explain that formaldehyde acted on rats' behavior by inducing an increase in anxiety level. This is in agreement with work that demonstrated behavioral sensitization produced after injection of formaldehyde in mice for 7 days, suggesting anxiety caused by formaldehyde (Li 2016); nevertheless, it had no batch significance (FV) and (FC) of day14.

On the other hand, when the identical batches from the two sessions were compared, the rats treated with the vehicle (FV) $\mathrm{J} 7$ and (FV) J14 also which were treated with curcumin (FC) day 7 with (FC) day 14.
We did notice an improvement in behavior at day 14 precisely in the batch that we treated with curcumin that presented itself with a very significant decrease at day 14 in the dark zone this

The results were consistent with the very significant increase in time spent in the clear zone. Behavioral tests were performed in epileptic rats with epilepsy induced by an intraperitoneal injection of a single dose of kainic acid and subsequently treated with curcumin. The epileptic rats treated with curcumin exhibited anxiolytic behaviors in the light/dark box test, which is less observed in rats treated with the vehicle (Yow et al 2017). Other research has measured certain behaviors related to anxiety-responses to examine the effects of curcumin on rats' anxiety symptoms (Lee and Lee 2018). Besides, turmeric also significantly reverses the cognitive and behavioral change in rats. (Huang et al 2011; Morrone et al 2016; Choi et al 2017).

The open-field test was used to evaluate the locomotion and rats' exploratory behavior. In this context, we chose two parameters to study, which are presented by the time spent in the peripheral zone and the central zone of this test's specific device. On day7, it was observed that the rats 
injected with formaldehyde spent more time in the peripheral zone and little time in the central zones. This explains why formaldehyde played the role of a stressful and exciting toxic product. Exposure to different FA concentrations in mice affects locomotor activity, depressive and anxious behavior, and cognition like other chemical aggressors (Li et al 2016). Thus, exposure of 2 ppm of FA in rats for a week significantly reduced locomotor activity in the open-field (Hoque et al 2018).

On day 14 , an improvement was certainly noticed in the batch treated with curcumin with a very highly significant increase between the (FC) day 14 and the (FC) day 7 of the time spent in the central zone, unlike the peripheral zone. Administer CUR to rats after involving prolonged stress by reversing serotonin (5-HT) dysfunction. Demonstrated a significant decrease in anxiety behaviors, as indicated by an increase in the number of central zone crossings during the open-field test. (Usanmaz et al 2002).

\section{Conclusions}

In this work, we demonstrated that curcumin's oral administration, one of the spices used as a natural treatment in Wistar rats, reveals preventive efficacy against anxiety induced by single intraperitoneal injection formaldehyde. We used two behavioral tests with these results to prove our expectations: the open-field test and the light and dark box.

\section{Conflict of Interest}

The authors declare that there are no conflict of interest with this work.

\section{Funding}

This research did not receive any financial support.

\section{References}

Arrant AE, Jemal H, Kuhn CM (2013) Adolescent male rats less sensitive than adults are to the antigenic and serotonin releasing effects of fenfluramine. Neuropharmacology 65:213-22.

Ben Ahmed A (2016) Etude de l'activite anxiolytique de l'extrait pib001 chez la souris. Mémoire de master, Université D'Antananarivo.

Choi GY, Kim HB, Hwang ES, Lee S, Kim MJ, Choi J Y, Lee SO, Kim SS, Park JH (2017) Curcumin alters neural plasticity and viability of intact hippocampal circuits and attenuates behavioral despair and COX-2 expression in chronically stressed rats. Mediators of inflammation.

Erika R (2015) ANALYSE DU MARCHÉ IMMOBILIER MONTRÉALAIS : LA PLACE DU BÂTIMENT DURABLE Essai présenté au Centre universitaire de formation en environnement et développement. Maîtrise en environnement. Centre Universitaire de Formation en environnement et développement durable.
Esmaily H, Sahebkar A, Iranshahi M, Ganjali S, Mohammadi A, Ferns G, Ghayour-Mobarhan M (2015) An investigation of the effects of curcumin on anxiety and depression in obese individuals: A randomized controlled trial. Chinese journal of integrative medicine 21:332-338.

Hall CS (1934) Emotional behavior in the rat. I. Defecation and urination as measures of individual differences in emotionality. Journal of Comparative Psychology 18:385-403.

Hoque HMS, Irie H, Damiani A, Rawat P, Naja M (2018) First simultaneous observations of formaldehyde and glyoxal by MAX-DOAS in the IndoGangetic Plain region. Sola 14:159-164. doi.org/10.2151/sola.2018-028.

Huang Z, Zhong XM, Li ZY, Feng CR, Pan AJ, and Mao QQ (2011) Curcumin reverses corticosterone-induced depressive-like behavior and decrease in brain BDNF levels in rats. Neuroscience letters 493:145-148.

Lan Q, Smith MT, Tang X, Guo W, Vermeulen R, Ji Z, Hu W, Hubbard AE, Shen M, McHale CM, Qiu C , Liu S , Reiss B ,Beane-Freeman L , Blair A, Ge Y ,Xiong J , Li L ,Rappaport SM, Huang H, Rothman N , Zhang L (2015) Chromosomewide aneuploidy study of cultured circulating myeloid progenitor cells from workers occupationally exposed to formaldehyde. Carcinogenesis 36:160167.

Lee B, Lee H (2018) Systemic administration of curcumin affect anxietyrelated behaviors in a rat model of posttraumatic stress disorder via activation of serotonergic systems. Evidence-Based Complementary and Alternative Medicine.

Li Y, Song Z, Ding Y, Xin Y, Wu T, Su T, He R, Tai F, Lian Z (2016) Effects of formaldehyde exposure on anxiety-like and depression-like behavior, cognition, central levels of glucocorticoid receptor and tyrosine hydroxylase in mice. Chemosphere 144:2004-2012.

Lopresti AL, Drummond PD (2017) Efficacy of curcumin, and a saffron/curcumin combination for the treatment of major depression: $A$ randomised, double-blind, placebo-controlled study. Journal of affective disorders 207:188-196.doi.org/10.1016/j.jad.2016.09.047

Mahmoud AL, Fenghour M (2016) Etude de l'effet protecteur d'un produit de la ruche, la gelée royale sur le Stress oxydatif et l'inflammation induit par le formaldéhyde chez le rat. Université des Frères Mentouri Constantine.

Morrone MDS, Schnorr CE, Behr GA, Gasparotto J, Bortolin RC, Moresco KS, Bittencourt L, Zanotto-Filho A, Gelain DP, Moreira JCF (2016) Oral administration of curcumin relieves behavioral alterations and oxidative stress in the frontal cortex, hippocampus, and striatum of ovariectomized Wistar rats. The Journal of nutritional biochemistry 32:181-188.

Motterlini R, Foresti R, Bassi R, Green CJ (2000) Curcumin, an antioxidant and anti-inflammatory agent, induces heme oxygenase-1 and protects endothelial cells against oxidative stress. Free Radical Biology and Medicine 28:1303-1312.

Usanmaz SE, Akarsu ES, Vural N (2002) Neurotoxic effects of acute and subacute formaldehyde exposures in mice. Environmental Toxicology and Pharmacology 11:93-100.doi.org/10.1016/S1382-6689(01)00109-.

Wang X, He R (2017) Formaldehyde Exposure and Neuropsychiatric Disorders. Formaldehyde and Cognition 191-207. Doi10.1007978-94-0241177-5_10.

World Health Organization (2017) Depression and other common mental disorders: Global health estimates. Geneva: World Health Organization.

Yow HY, Ahmad N, Azmi N, Bakry MM (2017) the effect of curcumin on anxiety and recognition memory in kainate model of epileptic rats. Indian Journal of Pharmaceutical Sciences 79:267-276. 